\title{
Demonstrating Pre-service Teacher Learning through Engagement in Global Field Experiences
}

\author{
Raymond W. Francis \\ Department of Teacher Education and Professional Development, Central Michigan University, USA
}

Copyright (C) 2015 by authors, all rights reserved. Authors agree that this article remains permanently open access under the terms of the Creative Commons Attribution License 4.0 International License

\begin{abstract}
Global opportunities for students to engage in teaching and learning have the potential to have a great impact on their professional knowledge base as a future teacher. However, little information is available about how global field experiences impact pre-service teachers' understanding due to substantial challenges in collecting and analyzing authentic student growth as a direct result of engaging in global field experiences. Due to the consistent growth demonstrated by all members of the study, and the key statistical significant differences between the pre-experience and post-experience groups, as well as within the pre-experience and post-experience groups, it is likely that the global field experience participated in by all pre-service teachers had a positive impact on students' growth and understanding of effective teaching. Of course additional study is needed. However, it appears that global field experiences have the potential to impact student growth and learning in an important manner.
\end{abstract}

Keywords Global Learning, Field Experiences, Teacher Education, Teacher Preparation

\section{Introduction}

Global opportunities for students to engage in teaching and learning have the potential to have a great impact on their learning and development as a teacher. However, little information is available about how global field experiences impact student understanding due to substantial challenges in collecting and analyzing authentic student growth as a direct result of engaging in global field experiences.

One specific style of instrument that may provide effective insights into student growth as a result of a global field experience is a concept map. Concept maps provide an outstanding avenue to promote students to demonstrate learning and growth in their teacher preparation programs. These authentic, student developed visual maps provide a unique pictorial representation of an individual's understanding of concepts and ideas, and promote communication and success.

In this project student developed concept maps are used to explore student growth and understandings as a result of participation in a short duration global field experience.

\section{Context of the Study}

The use of concept maps is not new. Concept maps have been used for many years, with published research on the topic including studies from the 1980s. A 2004 study [1] study linked the improvement of student performance to the use of concept mapping. A West Virginia (USA) study on graphic organizers use in Literacy [2] demonstrated that students using graphic organizers retained and used vocabulary terms more frequently than students not involved with graphic organizers. Also, other research demonstrated that significant differences in learning and application of major concepts existed between students using graphic organizers and those who did not use a form of graphic organizer in their studies [3]. In fact, concept maps and graphic organizers have been used in fields such as engineering, mathematics, medicine and health professions, marketing, and many others to examine authentic assessments and determine participant levels of performance. In addition, the concept maps and graphic organizers provided an authentic view of participant knowledge, and thus a road map for revising and reconfiguring programs in many fields.

However, a review of published literature reveals that concept maps have been overlooked as effective communication tools in the supervision of student teachers. Although an informative and applicable form of authentic assessment, concept maps may have been passed by in favor of more quantitative assessment means. In addition, concept maps have been neglected as strategies in the examination of knowledge and understanding of pre-service teachers. Recent research indicates the growth and development of novice teacher is readily evidenced through the analysis of terms and ideas represented in concept maps [4]. In short, concept maps provide an avenue to assess learners and 
explore growth in professionals, and have been overlooked in many areas.

Concept maps fit into one of the many classes of visual organizers. Visual organizers include such forms as flow charts, cluster webs, T-charts, attribute maps, sequence charts, story maps, and many others. Each of these particular visual organizers can play an important role in the classroom. However, concept maps provide a particularly meaningful set of uses in the student teaching experience. The concept map flows from the understanding of the pre-service teacher and is an authentic representation of the pre-service teacher's professional knowledge base on a specific topic. The authentic and personal nature of the concept map provides an effective assessment of the individual's understanding of a given topic or concept. In particular the semantic map, also known as a concept map, bubble map, or spider chart, allows the pre-service teacher the opportunity to organize and share information about a topic. In addition, it then allows the evaluator or researcher, the opportunity to see how the pre-service teacher is organizing and linking information. Once identified, faculty can work with pre-service teachers to revise understandings, build new links and connections, and expand their professional knowledge base of classroom teaching.

Concept maps are typically constructed by students to represent an idea or concept. Normally, there is a central idea or prompt being used as a focal point of the concept map, for example classroom management. Student teachers then generate terms connected to the central idea for the expanding levels of the concept map. Each succeeding level away from the central topic becomes more factual and less general. Chart 1 is a sample concept map for a student teacher prior to starting the student teaching experience.

Concept maps can reveal several things about a student teacher. Overall the student's "breadth of understanding" can be demonstrated by the number of entries attached to a particular term. In Chart 1 there are seven topics connected to the main topic (Classroom Management). These Level 1 entries demonstrate an above average number of entries in a pre-student teaching concept map [5]. However, there are few entries connected to each of the Level 1 entries. This indicates the student teacher is not demonstrating a "depth on knowledge" on the topic.

By comparison, Chart 2 is a concept map from a different student teacher that demonstrates a different level of understanding. This map also shows seven entries at Level 1. However, there are many more Level 2 and Level 3 entries throughout the artifact. In addition, this map demonstrates at least two connections between separate Level 1 and Level 2 entries. This map indicates a student teacher with a good "breadth of understanding" of the topic, as well as a sufficient "depth of knowledge" to enable the student teacher to understand and grow in their management of their classroom.

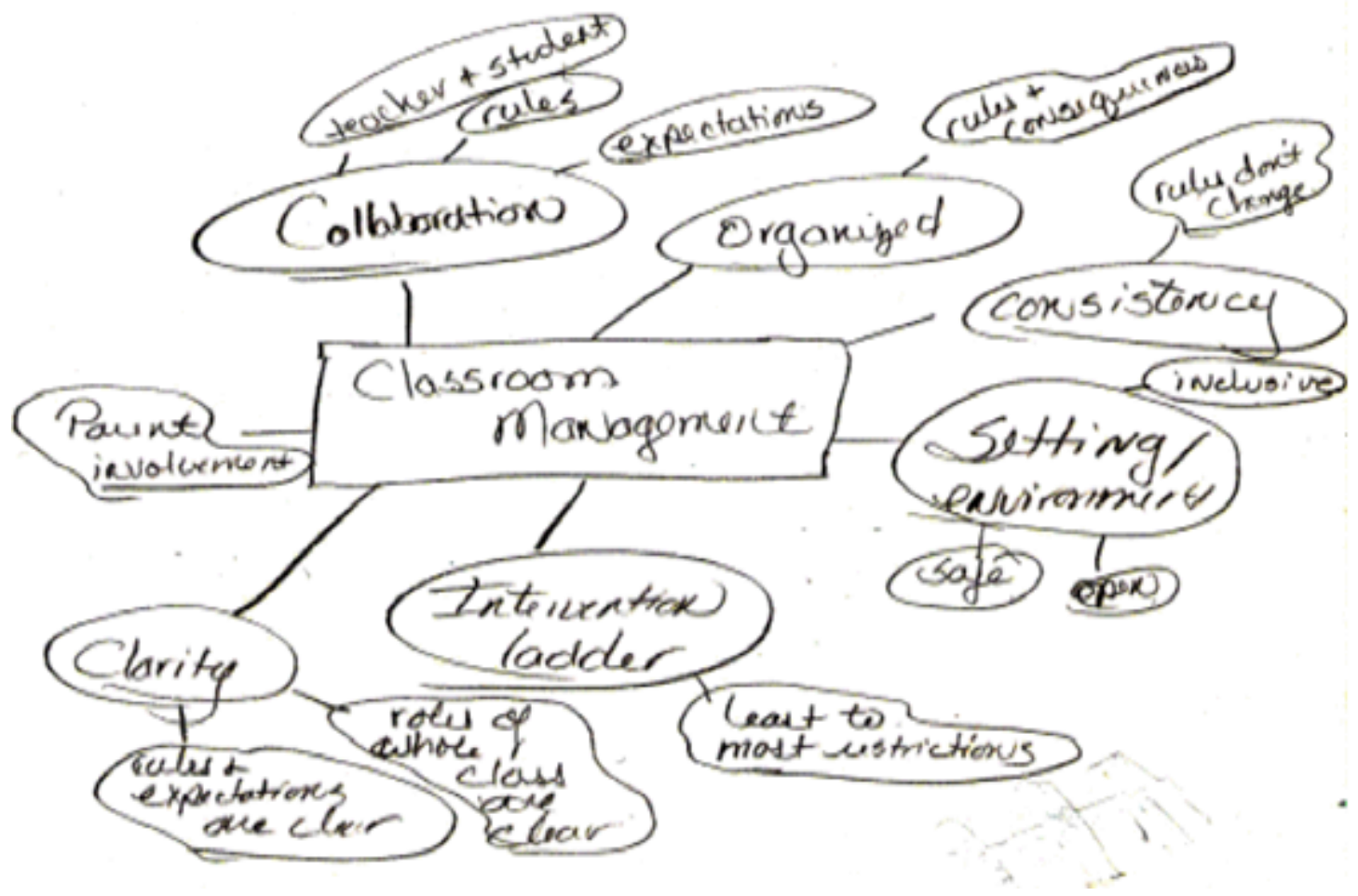

Figure 1. Sample Student Map (1) of Classroom Management 


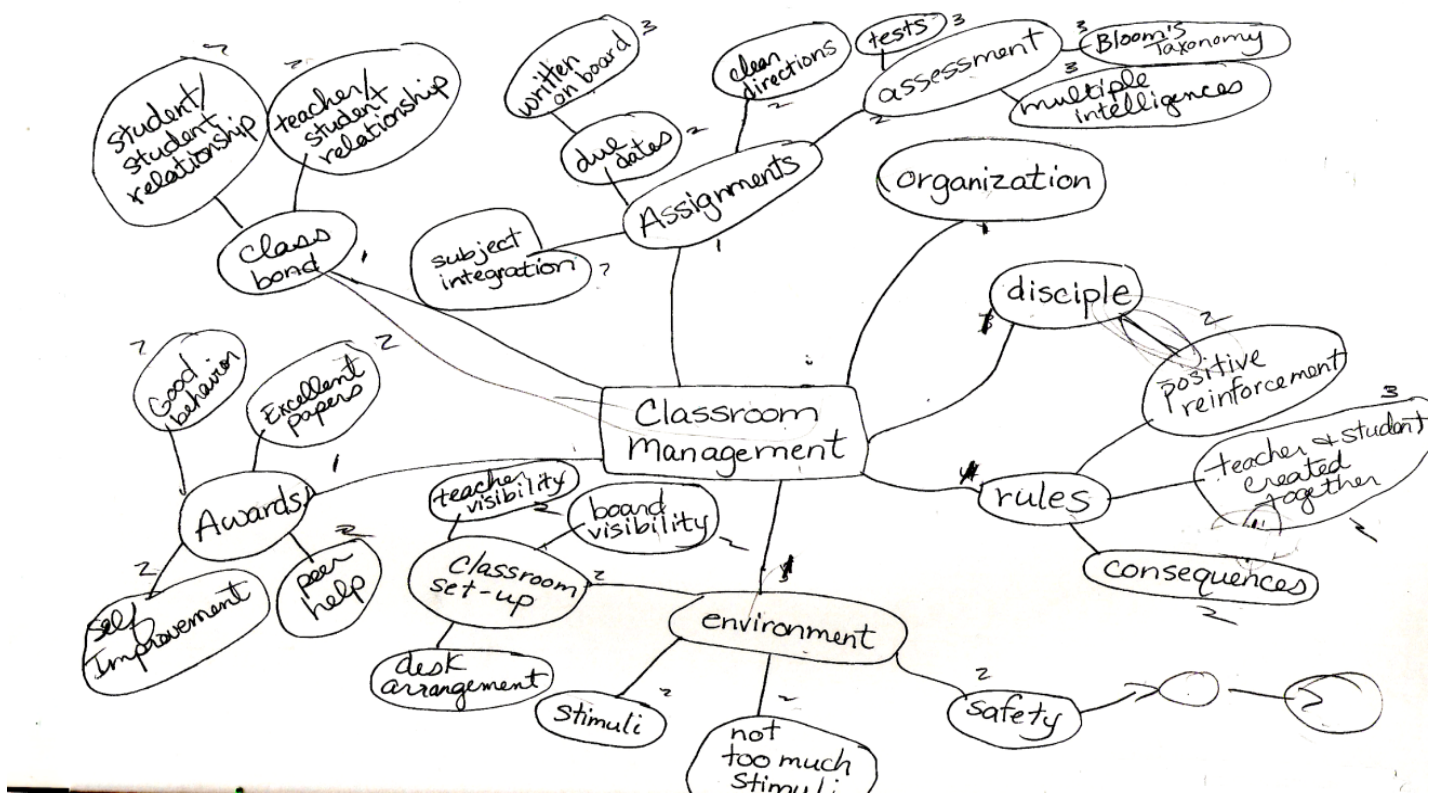

Figure 2. Sample Student Map (2) on Classroom Management

In the area of global field experiences the use of concept maps is particularly useful and informative. Since pre-service teachers are participating in a variety of experiences that are not a part of a larger group experience, the concept map provides a strategy to organize and evaluate the growing and changing professional knowledge base of pre-service teachers. These authentic concept maps then can become the representation of professional knowledge that allows pre-service teachers to explore and communicate about particular topics and ideas related to their global field experience.

\section{Methods}

As a part of this study a convenience sample of 29 students was identified. The student sample consisted of 18 elementary program, and 11 secondary program students, with all students participating in a short-term global field experience of 6 days of classroom experience in a non-American classroom.

As a part of data collection process all students completed a pre-experience concept map and a post-experience concept map on the topic of Effective Teaching. Each pre and post-experience map was coded by level and number of entries per level for the purpose of analysis. Once coded, all data was subjected to $\mathrm{s} 2$-tail student $\mathrm{t}$-test $(\mathrm{p}=.05)$ for all levels and overall totals.

\section{Results}

Data analysis provided a variety of opportunities for review and exploration. In reviewing the totals and means for the Pre-Experience data it was apparent that for both the pre and post-experiential data the number of entries increased between level 1 and level 2. However the data for the pre-experience data (Figure 3) decreased between level 2 and level 3, while the post-experience data demonstrated a relatively large increase between level 2 and level 3.

\begin{tabular}{|lllll|}
\hline Level & Pre-Exp & Pre-Exp & Post-Exp & Post-Exp \\
& Total & Mean & Total & Mean \\
2 & 138 & 3.83 & 192 & 5.33 \\
2 & 285 & 7.92 & 720 & 20 \\
3 & 135 & 3.75 & 828 & 45 \\
Overall & 558 & 15.5 & 1785 & 49.58 \\
\hline
\end{tabular}

Figure 3. Totals and Means of Pre-Experience and Post-Experience Concept Maps

In addition, calculated data for the Pre-Experience (Figure 4) and Post-Experience (Figure 5) demonstrate a relatively inconsistent measure. Standard deviations range has a range of 3.1 points for the pre-experience data and 8.5 points for the post-experience data. This data is most likely indicative of the large change in values for the various levels and supports the premise that growth and learning took place as a result of engaging in the global field experience.

\begin{tabular}{|c|c|c|c|c|}
\hline Level & Pre-1 & Pre-2 & Pre3 & Total \\
\hline Mean & 3.830 & 7.920 & 3.750 & 15.5 \\
\hline STD & 1.343 & 4.030 & 3.425 & 5.605 \\
\hline Stan Er & 0.227 & 0.681 & 0.618 & 0.947 \\
\hline
\end{tabular}

$\mathrm{Df}=36+36-2=70$

Critical value $=.95 \%$ or .05 confidence $=1.667$

Figure 4. Results for Pre-Instruction Assessment: Mean, Standard Deviation, and Standard Error. 


\begin{tabular}{|c|c|c|c|c|}
\hline Level & Post-1 & Post-2 & Post-3 & Total \\
\hline Mean & 5.330 & 20.0 & 23.0 & 49.58 \\
\hline STD & 2.134 & 5.701 & 10.684 & 12.419 \\
\hline Stan Er & 0.361 & 0.963 & 1.806 & 2.098 \\
\hline
\end{tabular}

$\mathrm{Df}=36+36-2=70$

Critical value $=.95 \%$ or .05 confidence $=1.667$

Figure 5. Results for Post-Instruction Assessment: Mean, Standard Deviation, and Standard Error.

Overall, statistical analysis of the data yielded several noteworthy results that are presented in Figure 6. First, The basic level of entries for both the pre and post-experience concept maps was similar for both groups. However, for level 2 pre and post groups, there was a significant difference in the number of entries with the mean for the pre group being significantly smaller than the mean for the post group.

This general trend continues with significant differences evident between the Pre level 2 and Pre level 3 groups, $(\mathrm{p}=9.5127)$ as well as the Pre and Post level 2 groups, and the Pre and Post level 3 groups ( $\mathrm{p}=16945)$. It should be noted that there were level 4 results for the Post-experience group, and none results for level 4 for the Pre-Experience group. While there was no significant difference between the Pre level 1 and level 3 data, there is a substantial statistical result for the Post level 1 and level 3 (groups ( $p=9.8487$ )

\begin{tabular}{|c|c|c|}
\hline Comparisons & & $\begin{array}{c}95 \% \\
\mathrm{P}=1.667\end{array}$ \\
\hline Pre-1 vs Pre-2 & 1.2739 & \\
\hline Pre-1 vs Pre-3 & 0.9084 & \\
\hline Pre-2 vs Pre-3 & 7.5127 & Sig dif \\
\hline & & \\
\hline Post-1 vs Post-2 & 1.1519 & \\
\hline Post-1 vs Post-3 & 9.8487 & Sig dif \\
\hline Post-2 vs Post-3 & 0.0994 & \\
\hline & & \\
\hline Overall Pre vs Post & 2.8396 & Sig dif \\
\hline & & \\
\hline Pre-1 vs Post-1 & 0.0003 & \\
\hline Pre-2 vs Post-2 & 1.6945 & Sig Dif \\
\hline Pre-3 vs Post 3 & 1.6888 & Sig Dif \\
\hline
\end{tabular}

Figure 6. 2-Tail t-Test results for Pre \& Post-Experience Entries

In addition, there is a notable significant difference between the overall Pre and Post-Experience groups $(p=2.8396)$. The results presented in Figure 6 are available in more visual options in Figure 7 and Figure 8, with the information clearly different between the Pre-Experience and Post-Experience collected data.

\section{Pre vs Post Instruction of Average Entries per Concept Map Level}

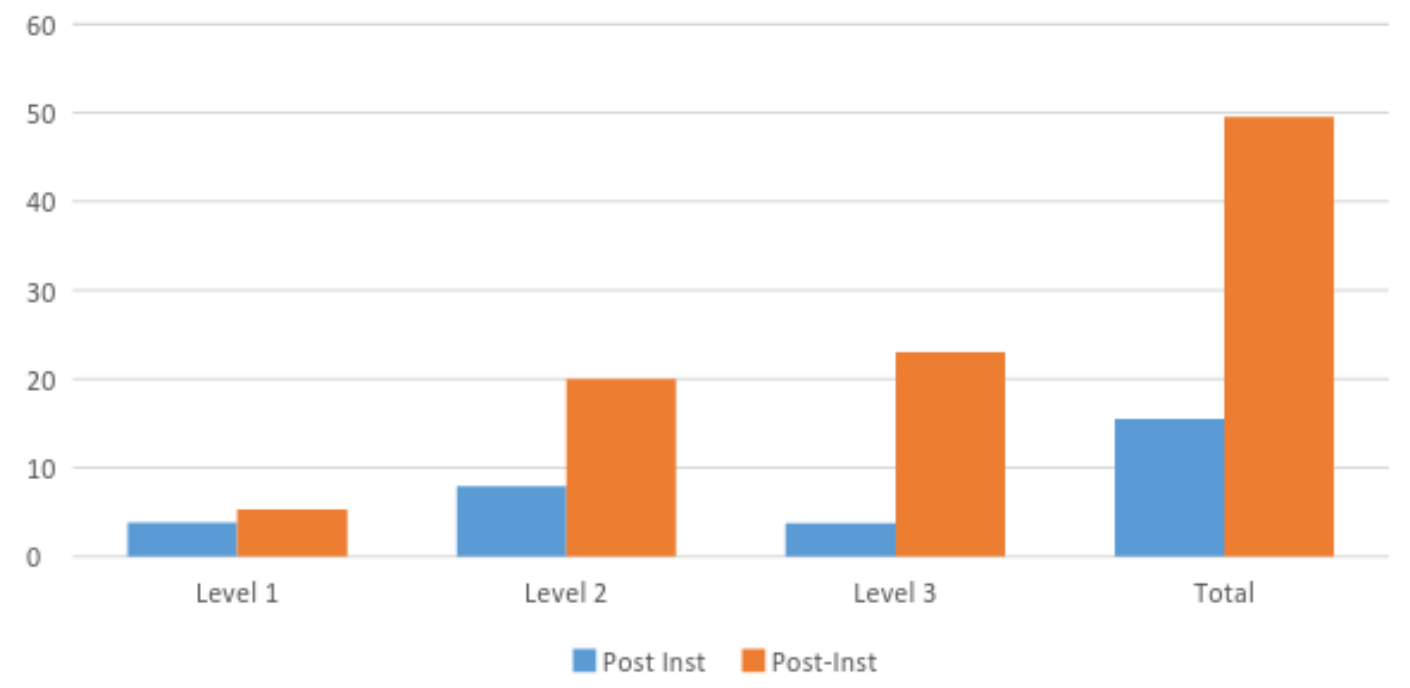

Figure 7. Graph of Pre vs Post Means of Entries Per Level (Bar chart) 


\section{Pre vs Post Instruction of Average Entries per Concept Map Level}

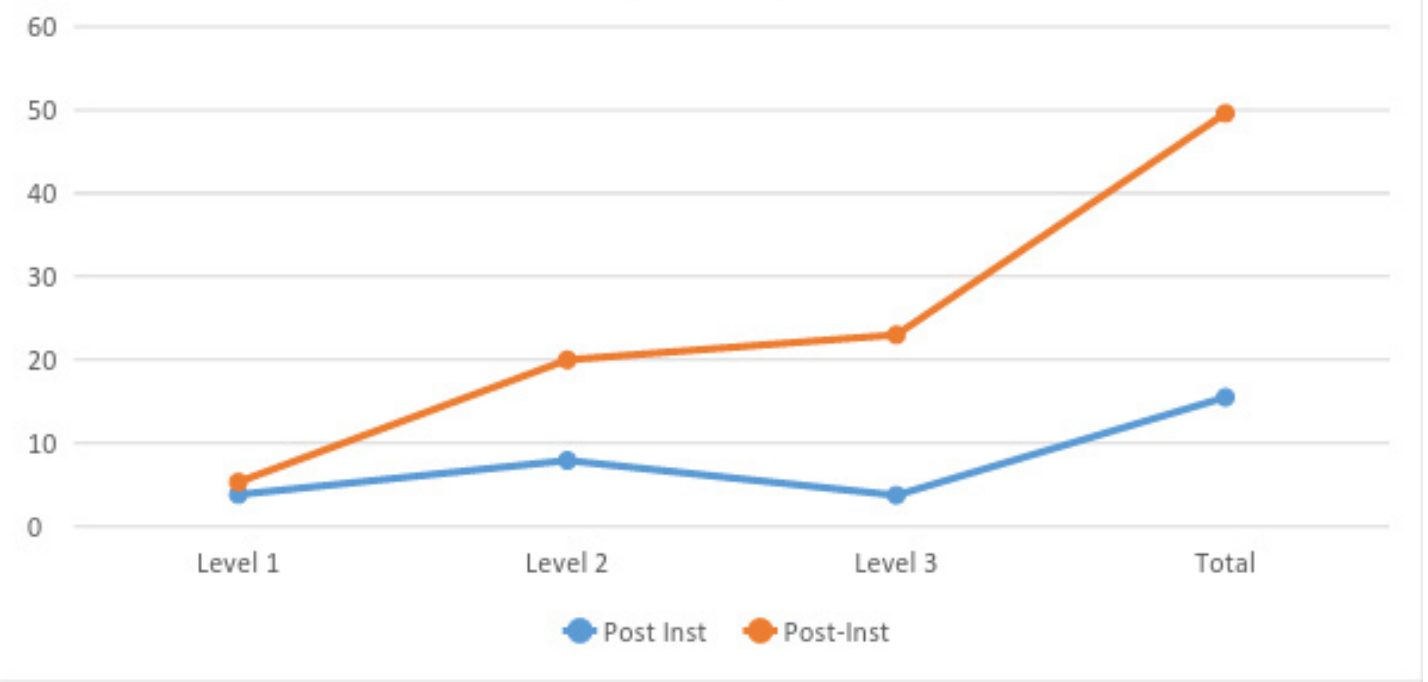

Figure 8. Pre vs Post-Instruction of mean entries per concept map level (Line chart)

\section{Conclusions}

From the analysis of the data it is apparent that there was a change in the understanding of the students about effective teaching, and how they were able to articulate these changes. This is identifiable through overall larger values in key areas. The greater number of entries on the concept maps, as well as the greater number of entries for any series of connections demonstrates a deeper understanding and application of available knowledge.

In this project, concept maps developed as a part of the pre-experience and post-experience process have been shown to demonstrate student growth and understanding in at least four substantial ways in their preparation for being a classroom teacher.

First, students participating in the study demonstrated, $100 \%$ of the time a growth in their understanding of what it takes to be an effective teacher. This conclusion is based on the overwhelming comparative data, as well as the organization of the study where the key event in the program for students between the pre-experience and post-experience development of the concept maps was the global field experience.

Second, the hearty significant differences between pre-experience and post-experience entries on the concept maps at the level 2 and level 3 are indicative of student learning, and an enhanced processing of information. These significant differences indicate the students were building and expanding their understanding of effective teaching while engaged in their global field experience.

Third, there was a very strong significant difference demonstrated between the post-experience level 1 and level 3 entries. This indicates that students processed the information not as a breadth of understanding, but rather as a depth of knowledge. Students are likely to retain these types of knowledge throughout their preparation program and into their professional practice.

Lastly, the overall pre-experience and post-experience means, and the statistically significant difference between the pre-experience and post-experience overall number of entries demonstrate growth and understanding by all students in the group as a result of participation in a short term global field experience.

Due to the consistent growth demonstrated by all members of the study, and the key statistical significant differences between the pre-experience and post-experience groups, as well as within the pre-experience and post-experience groups, it is likely that the global field experience participated in by all students had a positive impact on students' growth and understanding of effective teaching. Of course additional study is needed. However, it appears that global field experiences have the potential to impact student growth and learning in an important manner.

\section{REFERENCES}

[1] Holland, B., Holland, L., \& Davies, L (2005). An investigation into the concept of mind mapping and the use of mind mapping software to support and improve student academic performance. Taken from the internet on 7/1/2014 from the URL:

http://wlv.openrepository.com/wlv/bitstream/2436/3707/1/M ind\%20mapping\%20pgs\%2089-94.pdf.

[2] West Virginia Department of Education (2014). Vocabulary Graphic Organizers. Taken from the internet on June 10, 2014 from the URL:

http://wvde.state.wv.us/strategybank/VocabularyGraphicOrg 
anizers.html

[3] Bernard, K. (2013). Research based education strategies and methods. Taken from the internet on June 4, 2014 from the URL:

http://makingeducationfun.wordpress.com/2012/03/28/graph ic-organizers/

[4] Francis, R.W. (July 2013). Using concept maps as assessment tools: defining understanding. A paper presented at the Lilly North Conference on College Teaching and Learning. Traverse City, MI (Sept, 2013).

[5] Francis, R.W. (July 2013). Using concept maps as assessment tools: defining understanding. A paper presented at the Lilly North Conference on College Teaching and Learning. Traverse City, MI (Sept, 2013). 